\title{
Yoga and Hypertension
}

\author{
Debbie L Cohen ${ }^{*}$ \\ Perelman School of Medicine at the University of Pennsylvania, Renal, Electrolyte and \\ Hypertension Division, USA
}

\begin{abstract}
Hypertension is a major public health issue affecting more than 70 million US adults and is a major risk factor in the development of stroke, cardiovascular [CV] and chronic kidney disease [1]. Patients with prehypertension [BP 130-130/80-89 $\mathrm{mmHg}$ [ [2] are also at an increased risk for adverse $\mathrm{CV}$ events compared to normotensive controls [3]. Lifestyle modifications [LSM] have been recommended as a first line approach for both prehypertension and stage 1 hypertension patients [2]. Complementary and Alternative Medicine $[\mathrm{CAM}]$ modalities including mind-body therapies have been used in managing modest elevations in BP [4]. Yoga has been shown to be one of the most popular CAM therapies with growing use particularly in older hypertensive patients [5-8]. Although yoga has been beneficial in treating a variety of medical conditions $[9,10]$ there has been limited data published suggesting a benefit of yoga on hypertension.
\end{abstract}

Although there are a number of published studies investigating the effects of various forms of yoga on hypertension [4,11-23], most of these studies are uncontrolled case reports or small cohort studies conducted in India with significant methodological limitations. There are only 9 randomized controlled trials [RCT] of any form of yoga for hypertension $[11,13,15-21,23]$. They are shown in Table 1 . This includes our own previous study completed at the University of Pennsylvania in which subjects with prehypertension to stage 1 hypertension were randomized to a structured Iyengar Yoga [IY] Program or enhanced LSM. This study showed clinically meaningful reductions in 24-hour ambulatory BP readings in the IY group at 12 weeks [17]. The most recent publication from Canada randomized unmedicated stage 1 hypertensive patients to meditation and yoga for 8 weeks versus wait-list control [20]. Ambulatory BP monitoring was performed at baseline and at 12 weeks. Results of ABP did not lower BP by a statistically or clinically meaningful amount in the treatment group as opposed to the control group. Another recent study from St Louis of $60 \mathrm{HIV}$ infected adults with moderate CVD and with $83 \%$ of subjects with hypertension were assigned to 20 weeks of supervised yoga practice or standard of care treatment. Resting SBP and DBP improved more in the yoga group than in the standard of care group [21]. A recent study from India was a cross-over RCT of an earlier RCT of nonpharmacological interventions in hypertension. Subjects were prehypertensive adults who were randomly allotted to a group that they had not been in the previous trial [19]. They

This is an open-access article distributed under the terms of the Creative Commons Attribution License, which permits unrestricted use, distribution, and reproduction in any medium, provided the original author and source are credited.

*Corresponding author: Debbie L Cohen, MD, Perelman School of Medicine at the University of Pennsylvania, Renal, Electrolyte and Hypertension Division, 1 Founders Building, 3400 Spruce Street, Philadelphia, PA, USA, 19104, Tel: 215-6150794;

debbie.cohen@uphs.upenn.edu. 
were assigned to one of 4 groups for 8 weeks: control group, brisk walking 50-60 minutes 3-4 days a week, sodium restriction to at least half of their previous intake or yoga for 30-45 minutes per day, 5 days per week. All 3 groups aside from the control group showed reduction in BP but physical exercise showed a greater reduction on BP in the range of 5/6 $\mathrm{mm} \mathrm{Hg}$ whereas sodium reduction and yoga showed a less impressive decline in BP in the range of 2.5/2.0 $\mathrm{mm} \mathrm{Hg} \mathrm{[18].} \mathrm{Another} \mathrm{study} \mathrm{involved} 101$ subjects with features of the metabolic syndrome who were randomized to standard medical therapy or yoga and a form of transcendental meditation. SBP was reduced significantly by $16 \mathrm{~mm} \mathrm{Hg}$ in the treatment group [23]. Another prior study was an 8 week pranayama and asana yoga program conducted in 27 untreated hypertensive patients and 27 controls living in Tailand [11]. The experimental group significantly reduced SBP by $25 \mathrm{~mm} \mathrm{Hg}$ at 8 weeks compared to $2 \mathrm{~mm}$ $\mathrm{Hg}$ increase in the control group. DBP significantly decreased by $18 \mathrm{~mm} \mathrm{Hg}$ in the experimental group compared to an increase of $2 \mathrm{~mm} \mathrm{Hg}$ in the control group. In India, 33 hypertensive adults were randomly assigned to 3 groups [yoga, medications only, or no therapy] and were followed for 11 weeks [15]. Yoga was performed at home for 6 hours per week and included a combination of asanas, pranayamas and mantras. At the end of the study, SBP was reduced by an impressive $33 \mathrm{mmHg}$ compared to $4 \mathrm{mmHg}$ in the control group and $24 \mathrm{mmHg}$ in the poorly described drug therapy group. The differences were significant compared to both control and drug treatment. In an older randomized controlled trial from England, 43 patients with known hypertension, most of whom were already medically treated, were randomized to yoga plus biofeedback or usual care [16]. Treatment reduced SBP by $26 \mathrm{mmHg}$ vs. $9 \mathrm{mmHg}$ in the control. This study however used a mixed intervention which included biofeedback in addition to yoga, and did not include any movement.

A general critique of the published yoga and hypertension research includes the fact that most studies were not randomized, had inadequately described yoga or control programs, did not collect information on other lifestyle confounders [e.g. adoption of vegetarian diet, reduction in alcohol intake] and did not use standardized, reliable outcomes measures. There is also the very real possibility of publication bias in which negative yoga trials have not been published. Some of the older studies also report much more impressive reductions in $\mathrm{BP}$ than one would expect with a lifestyle intervention and this does question the validity of the data. Most lifestyle interventions including regular aerobic exercise, dietary sodium reduction and weight loss of $10 \mathrm{~kg}$ usually result in a BP reduction in the range of $4-10 \mathrm{~mm}$ $\mathrm{Hg}$ in SBP.

The effects of yoga on lowering blood pressure in more recent studies have mostly been modest however data from the Framingham Heart Study showed that a $2 \mathrm{~mm} \mathrm{Hg}$ reduction in DBP could reduce the risk of stroke or transient ischemic attack by $14 \%$ [24]. While a 10 $\mathrm{mm} \mathrm{Hg}$ reduction in SBP, seen with prescription drugs and in some meditation studies [25], is associated with a $30 \%$ relative reduction in risk of stroke [26]. Thus smaller reductions in BP [ $5 \mathrm{~mm} \mathrm{Hg}$ in SBP or $2 \mathrm{mmHg}$ in DBP] achievable through diet, some dietary supplements and mind body therapies can be expected to significantly reduce CVD morbidity. 
A recent meta-analysis was conducted of 17 randomized and non-randomized trials of yoga and hypertension. Results showed that yoga had a modest effect on both SBP [-4.17 $\mathrm{mm} \mathrm{Hg}$ ] and DBP [- $3.26 \mathrm{~mm} \mathrm{Hg}$ ]. There was substantial heterogeneity present across the included studies. The effects of yoga on BP varied by the type of yoga intervention and by comparison group but not by duration of yoga practice. When the analysis was restricted to studies using interventions incorporating three elements of yoga practice[postures, meditation and breathing] larger reductions of SBP and DBP [-8.17 $\mathrm{mmHg}$ and-6.14 $\mathrm{mmHg}$ ] were observed. Yoga was also associated with a significant decline in SBP and DBP [-7.96 $\mathrm{mm} \mathrm{Hg}$ and $-5.52 \mathrm{~mm} \mathrm{Hg}$ ] relative to no treatment but not when compared to exercise or other intervention types [27].

We are currently completing a randomized clinical trial of yoga utilizing gold standard methodologies in the measurement of BP to rigorously evaluate the efficacy of yoga in subjects with prehypertension and stage 1 hypertension. Enrollment goal is 120 subjects. Subjects are randomized to 1 of 3 treatment groups: yoga practice in a studio 2-3 $\times$ per week for 24 weeks versussupervised diet/weight reduction and walking program versus combination program consisting of both yoga and the dietary/walking program intervention. Subjects have inpatient ambulatory BP monitoring at baseline, 12 and 24 weeks [28]. The study will be completed by December 2013 .

There is a genuine need for rigorously conducted randomized clinical trials of yoga assessing the effects of lowering BP in patients with prehypertension and stage 1 hypertension. Even if the effects of yoga on hypertension are modest this can still provide substantial CV protection for this group of patients with mild to moderate hypertension and may afford patients the opportunity to engage in yoga instead of committing to lifelong antihypertensive medication.

\section{Acknowledgments}

Funding: NCCAM: 1RO1AT004921-01A1

\section{References}

1. Egan BM, Zhao Y, Axon RN. US trends in prevalence, awareness, treatment, and control of hypertension, 1988-2008. JAMA. 2010; 303:2043-2050. [PubMed: 20501926]

2. Chobanian AV, Bakris GL, Black HR, Cushman WC, Green LA, et al. The Seventh Report of the Joint National Committee on Prevention, Detection, Evaluation, and Treatment of High Blood Pressure: the JNC 7 report. JAMA. 2003; 289:2560-2572. [PubMed: 12748199]

3. Vasan RS, Larson MG, Leip EP, Evans JC, O'Donnell CJ, et al. Impact of high-normal blood pressure on the risk of cardiovascular disease. N Engl J Med. 2001; 345:1291-1297. [PubMed: 11794147]

4. Cohen D, Townsend RR. Yoga and hypertension. J Clin Hypertens (Greenwich). 2007; 9:800-801. [PubMed: 17917509]

5. Blanck HM, Serdula MK, Gillespie C, Galuska DA, Sharpe PA, et al. Use of nonprescription dietary supplements for weight loss is common among Americans. J Am Diet Assoc. 2007; 107:441-447. [PubMed: 17324663]

6. Nahin RL. Use of the best case series to evaluate complementary and alternative therapies for cancer: a systematic review. Semin Oncol. 2002; 29:552-562. [PubMed: 12516038] 
7. Cheung CK, Wyman JF, Halcon LL. Use of complementary and alternative therapies in communitydwelling older adults. J Altern Complement Med. 2007; 13:997-1006. [PubMed: 18047447]

8. Bell RA, Suerken CK, Grzywacz JG, Lang W, Quandt SA, et al. CAM use among older adults age 65 or older with hypertension in the United States: general use and disease treatment. J Altern Complement Med. 2006; 12:903-909. [PubMed: 17109582]

9. Dash M, Telles S. Improvement in hand grip strength in normal volunteers and rheumatoid arthritis patients following yoga training. Indian J Physiol Pharmacol. 2001; 45:355-3560. [PubMed: 11881576]

10. Kolasinski SL, Garfinkel M, Tsai AG, Matz W, Van Dyke A, et al. Iyengar yoga for treating symptoms of osteoarthritis of the knees: a pilot study. J Altern Complement Med. 2005; 11:689693. [PubMed: 16131293]

11. McCaffrey R, Ruknui P, Hatthakit U, Kasetsomboon P. The effects of yoga on hypertensive persons in Thailand. Holist Nurs Pract. 2005; 19:173-180. [PubMed: 16006832]

12. Damodaran A, Malathi A, Patil N, Shah N, Suryavansihi, et al. Therapeutic potential of yoga practices in modifying cardiovascular risk profile in middle aged men and women. $\mathrm{J}$ Assoc Physicians India. 2002; 50:633-640. [PubMed: 12186115]

13. Tulpule TH, Shah HM, Shah SJ, Haveliwala HK. Yogic exercises in the management of ischaemic heart disease. Indian Heart J. 1971; 23:259-264. [PubMed: 5146619]

14. Datey KK, Deshmukh SN, Dalvi CP, Vinekar SL. "Shavasan": A yogic exercise in the management of hypertension. Angiology. 1969; 20:325-333. [PubMed: 5789748]

15. Murugesan R, Govindarajulu N, Bera TK. Effect of selected yogic practices on the management of hypertension. Indian J Physiol Pharmacol. 2000; 44:207-210. [PubMed: 10846637]

16. Patel C. 12-month follow-up of yoga and bio-feedback in the management of hypertension. Lancet. 1975; 1:62-64. [PubMed: 46021]

17. Cohen DL, Bloedon LT, Rothman RL, Farrar JT, Galantino ML, et al. Iyengar Yoga versus Enhanced Usual Care on Blood Pressure in Patients with Prehypertension to Stage I Hypertension: a Randomized Controlled Trial. Evid Based Complement Alternat Med. 2011; 2011:546428. [PubMed: 19734256]

18. Subramanian H, Soudarssanane MB, Jayalakshmy R, Thiruselvakumar D, Navasakthi D, et al. Non-pharmacological Interventions in Hypertension: A Community-based Cross-over Randomized Controlled Trial. Indian J Community Med. 2011; 36:191-196. [PubMed: 22090672]

19. Saptharishi L, Soudarssanane M, Thiruselvakumar D, Navasakthi D, Mathanraj S, et al. Community-based Randomized Controlled Trial of Non-pharmacological Interventions in Prevention and Control of Hypertension among Young Adults. Indian J Community Med. 2009; 34:329-334. [PubMed: 20165628]

20. Blom K, How M, Dai M, Baker B, Irvine J, et al. Hypertension Analysis of Stress Reduction Using Mindfulness Meditation and Yoga: Results From the Harmony Randomized Controlled Trial. Am J Hypertens. 2013

21. Cade WT, Reeds DN, Mondy KE, Overton ET, Grassino J, et al. Yoga lifestyle intervention reduces blood pressure in HIV-infected adults with cardiovascular disease risk factors. HIV Med. 2010; 11:379-388. [PubMed: 20059570]

22. Lakshmikanthan C, Alagesan R, Thanikachalam S, Ramamurthi B, Elangovan D, et al. Long term effects of yoga on hypertension and/or coronary artery disease. J Assoc Physicians India. 1979; 27:1055-1058. [PubMed: 398852]

23. Khatri D, Mathur KC, Gahlot S, Jain S, Agrawal RP. Effects of yoga and meditation on clinical and biochemical parameters of metabolic syndrome. Diabetes Res Clin Pract. 2007; 78:e9-10. [PubMed: 17597249]

24. Whelton PK, He J, Appel LJ, Cutler JA, Havas S, et al. Primary prevention of hypertension: clinical and public health advisory from The National High Blood Pressure Education Program. JAMA. 2002; 288:1882-1888. [PubMed: 12377087]

25. Schneider RH, Staggers F, Alxander CN, Sheppard W, Rainforth M, et al. A randomised controlled trial of stress reduction for hypertension in older African Americans. Hypertension. 1995; 26:820 827. [PubMed: 7591024] 
26. Staessen JA, Gasowski J, Wang JG, Thijs L, Den Hond E, et al. Risks of untreated and treated isolated systolic hypertension in the elderly: meta-analysis of outcome trials. Lancet. 2000; 355:865-872. [PubMed: 10752701]

27. Hagins M, States R, Selfe T, Innes K. Effectiveness of yoga for hypertension: systematic review and meta-analysis. Evid Based Complement Alternat Med. 2013; 2013:649836. [PubMed: 23781266]

28. Cohen DL, Bowler A, Fisher SA, Norris A, Newberg A, et al. Lifestyle Modification in Blood Pressure Study II (LIMBS): Study protocol of a randomized controlled trial assessing the efficacy of a 24 week structured yoga program versus lifestyle modification on blood pressure reduction. Contemp Clin Trials. 2013; 36:32-40. [PubMed: 23721984] 


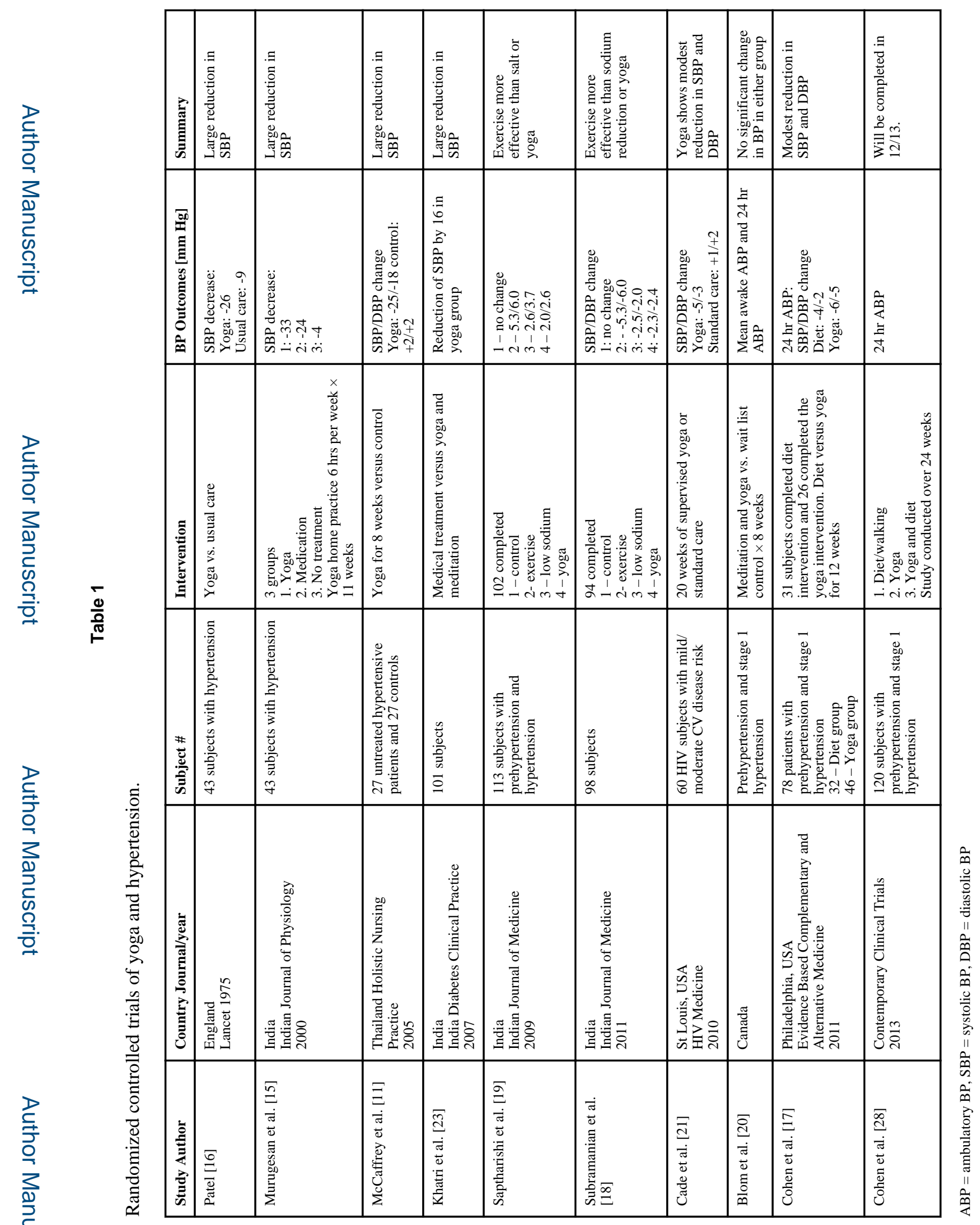

J Yoga Phys Ther. Author manuscript; available in PMC 2015 September 24. 